\title{
Toward zero waste production in the paint industry
}

\author{
LL Jewell ${ }^{\star 1}$, OA Fasemore ${ }^{1}$, D Glasser ${ }^{1}$, D Hildebrandt ${ }^{1}$, L Heron ${ }^{2}$, N van Wyk $^{2}$ and B Cooray ${ }^{2}$ \\ ${ }^{1}$ School of Process and Material Engineering, University of the Witwatersrand Private Bag 3, WITS 2050, South Africa \\ ${ }^{2}$ Barloworld Plascon South Africa (Pty) Limited, South Africa
}

\begin{abstract}
Wastewater is generated in the batch production process of water-based paints when vessels and filling lines are washed between batches. This results in a diluted paint wash water stream. The wash water is currently treated in a flocculation process using ferric chloride as a coagulant.

An opportunity was identified for re-using wash water from white, non-textured paints. It is necessary to stabilise the wash water with biocides. This water is then used in place of fresh feed water for lower quality paints. Since the wash water originates from high quality products, adding this water to the lower quality paints results in a quality improvement. In addition, treatment costs of the wash water are reduced. This wash water represents approximately $65 \%$ of total effluent from the plant.

With respect to the remainder of the wash water, the concentration of paint solids in the wastewater stream can vary widely. For effective treatment different solids content in the wastewater requires different dosage levels of the coagulant. If ferric chloride is used as the coagulant overdosing results in waste that must be disposed of as toxic. Ferric chloride dosing can be more easily controlled by using a dilute feed solution. This paper presents the findings of the effect of concentration of the coagulant on the coagulation process. Both the solids content of the wash water and the concentration of the coagulant have been found to be important variables to ensure efficient flocculation and coagulant utilisation.
\end{abstract}

\section{Introduction}

Although the type of waste generated by different industries varies dramatically the principles in waste minimisation are generic.

An approach known as the hierarchy of waste is being applied. The basic principle is that to avoid waste generation is far easier than to reprocess it later (Cano-Ruiz and McRae, 1998). The next level in the hierarchy is to simply reuse the waste material with almost no processing. A common example of this is the refilling of bottles after simply washing them. Recycling is the next level down and it implies that the waste stream is reprocessed to make it useful again. Again the analogy of a glass bottle being melted down to be formed into a new shape is useful. Potentially the most difficult waste reduction strategy is to reprocess the waste in such a way that it can be used in another unrelated process. This could however also prove to be a simple solution. It is clear that the further from the source of the waste one tackles the problem of waste minimisation, the more energy, technology and cost is required, and hence the more difficult it becomes to strive toward a zero waste system. The major driver for waste reduction is cost. The diagram that follows is a representation of the hierarchy of waste.

In the drive for zero waste Barloworld Plascon SA (Pty) Ltd has undertaken a number of initiatives to eliminate waste at source.

Two of these will be discussed in this paper, namely recycling wash water and the way in which effluent is treated prior to disposal.

Reusing the wash water is a desirable way to minimise the waste generated. This could be done in two different ways: the water could be reused as wash water, however this would result in

This paper was originally presented at the 2004 Water Institute of South Africa (WISA) Biennial Conference, Cape Town, South Africa, 2-6 May 2004.

* To whom all correspondence should be addressed.

面+2711 7177507 ; fax: +2711 7177557 ;

e-mail: Linda.jewell@comps.wits.ac.za

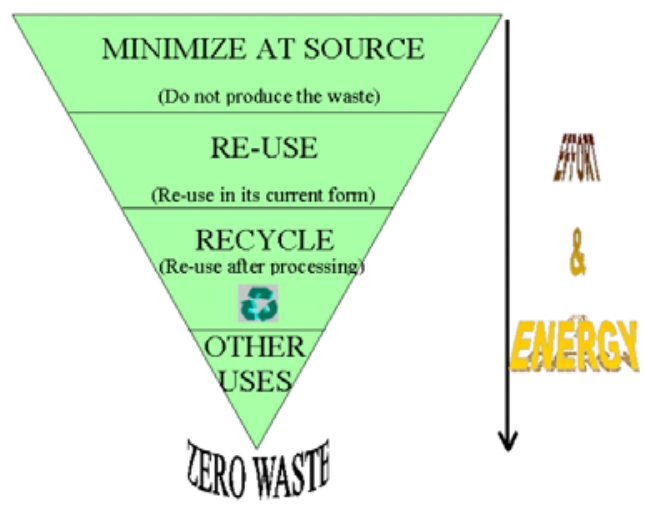

Figure 1

Hierarchy of waste

a fairly fast deterioration of the cleaning of vessels and lines, as the paint is a fairly concentrated suspension. The other alternative is to explore re-using the wash water instead of fresh water feed. The major concern that needs to be addressed is product quality which must not be affected by the reuse of the wash water.

For example depending on the origin of the wash water it may contain solids with undesirable properties like texture or colour which could affect product quality. Wash water with texture or colour could only be used in products with texture and colour. Moreover the wash water ferments and storage space is limited. In the light of this and the fact that the paint production schedule runs according to market demand for different products, not all of the water can be reused. The remainder must continue to be disposed of once it has been treated.

The wastewater generated is comprised of water and paint constituents (mainly solids that are suspended in the wastewater). This wastewater cannot be sent directly into the public sewage system because it does not meet the effluent discharge standards 
such as turbidity and solids content.

Solids are removed from the wastewater by means of coagulation and flocculation using ferric chloride. The solids content of the water is variable and the amount of ferric chloride required to flocculate the water is proportional to the solids content of the water. This sometimes leads to ferric chloride overdosing. When this occurs the water must be disposed of as toxic due to the high $\mathrm{Fe}^{3+}$ concentration. It is expensive to dispose of toxic waste, so that eliminating overdosing represents a considerable cost saving to the company. The sludge must also be disposed of. The thinking around the re-using or recycling of the sludge waste into a product that is useful to the paint or other industries is still in its infancy. The solids in paint can be divided into two categories: particles that settle out under gravity in a matter of hours (ca. $10 \mathrm{~mm}$ in diameter) and particles that form a colloidal suspension (ca. $0.1 \mathrm{~mm}$ in diameter) (Peavy, Rowe and Tchobanoglous, 1985). Coagulation is defined as the destabilisation of a colloidal suspension, and flocculation as the subsequent agglomeration of small particles into flocs that settle out relatively fast. These two processes are combined to separate colloidal suspensions into a sludge that contains the solids and clear liquid.

Coagulation is achieved by adding a coagulant to the water to be treated. Different types of coagulants include organic surfactant type molecules or inorganic salts, usually of iron or aluminium. When added to water these salts hydrolyse to form a range of hydrolysis species (Jiang and Graham, 1998). Flynn (1984) has proposed that the following reactions occur:

$$
\begin{array}{lll}
\mathrm{Fe}^{3+}+\mathrm{H}_{2} \mathrm{O} \leftrightarrow \mathrm{FeOH}^{2+}+\mathrm{H}^{+} & \log \mathrm{K}\left(25^{\circ} \mathrm{C}\right)=-2.2 & {[1]} \\
\mathrm{FeOH}^{2+}+\mathrm{H}_{2} \mathrm{O} \leftrightarrow \mathrm{Fe}(\mathrm{OH})_{2}^{+}+\mathrm{H}^{+} & \log \mathrm{K}\left(25^{\circ} \mathrm{C}\right)=-3.5 & {[2]} \\
\mathrm{Fe}(\mathrm{OH})_{2}^{+}+\mathrm{H}_{2} \mathrm{O} \leftrightarrow \mathrm{Fe}(\mathrm{OH})_{3}+\mathrm{H}^{+} & \log \mathrm{K}\left(25^{\circ} \mathrm{C}\right)=-6 & {[3]} \\
\mathrm{Fe}(\mathrm{OH})_{3}+\mathrm{H}_{2} \mathrm{O} \leftrightarrow \mathrm{Fe}(\mathrm{OH})_{4}^{-}+\mathrm{H}^{+} & \log \mathrm{K}\left(25^{\circ} \mathrm{C}\right)=-10 & {[4]} \\
2 \mathrm{Fe}^{3+}+2 \mathrm{H}_{2} \mathrm{O} \leftrightarrow \mathrm{Fe}_{2}(\mathrm{OH})_{2}^{4+}+2 \mathrm{H}^{+} & \log \mathrm{K}\left(25^{\circ} \mathrm{C}\right)=-2.9 & {[5]} \\
3 \mathrm{Fe}^{3+}+4 \mathrm{H}_{2} \mathrm{O} \leftrightarrow \mathrm{Fe}_{3}(\mathrm{OH})_{4}{ }^{5+}+4 \mathrm{H}^{+} & \log \mathrm{K}\left(25^{\circ} \mathrm{C}\right)=-6.3 & {[6]} \\
\mathrm{Fe}(\mathrm{OH})_{3}(\mathrm{am}) \leftrightarrow \mathrm{Fe}^{3+}+3 \mathrm{OH}^{-} & \log \mathrm{K}\left(25^{\circ} \mathrm{C}\right)=-37.1 \\
& \text { to } 39.0 & \\
\alpha-\mathrm{FeOOH}(\mathrm{c})+\mathrm{H}_{2} \mathrm{O} & \log \mathrm{K}\left(25^{\circ} \mathrm{C}\right)=-41.7 \\
\leftrightarrow \mathrm{Fe}^{3+}+3 \mathrm{OH}^{-} &
\end{array}
$$

According to Flynn (1984) and Magini (1977) most of these reactions occur slowly, although of course the rate of any reaction can be accelerated by increasing the concentration of the reactants or the temperature of the reaction. In addition, unacidified Fe(III) salt solutions are unstable with respect to precipitation of amorphous hydrous iron oxides at all concentrations. As can be clearly seen from reactions 1 to 6 , the hydrolysis of the iron species releases $\mathrm{H}^{+}$ions which means that the $\mathrm{pH}$ of these solutions is acidic.

The higher the initial ferric ion concentration the more acid the solution. The precipitation of amorphous $\mathrm{Fe}(\mathrm{OH})_{3}$ is preceeded by the formation of spherical polymeric Fe species. The exact formula of these species is not known, although there is evidence that they consist of octrahedral $\mathrm{FeO}_{6}$ unit cells (Magini, 1977). These species agglomerate to form needle-like structures which in turn form plates (Flynn, 1984). The polymeric species can be represented as $\mathrm{Fe}_{\mathrm{x}}(\mathrm{OH})_{\mathrm{y}}^{(3 \mathrm{x}-\mathrm{y})^{+}}$and/or $\left[\mathrm{Fe}_{\mathrm{x}} \mathrm{O}_{\mathrm{y}}(\mathrm{OH})_{\mathrm{x}+\mathrm{r}}\right]^{(2 \mathrm{x}-2 \mathrm{y}-\mathrm{r})^{+}}$(Jiang and Graham, 1997).

It appears that these polymeric species, rather than forming hydroxide precipitates, can also adsorb to colloidal particles due to attractive electrostatic charges (Jiang and Graham, 1998) so that they are the active species in coagulation. This is corroborated by evidence that when aluminium salts are used as coagulants the active species is the polymeric $\mathrm{Al}_{13} \mathrm{O}_{4}(\mathrm{OH})_{28}\left(\mathrm{H}_{2} \mathrm{O}\right)_{8}{ }^{3+}$ ion (Bottero et al., 1980).
Thus there is competition between the phenomena that lead to coagulation/flocculation and direct hydroxide precipitation of the coagulant. The lower the $\mathrm{pH}$, the less favourable the precipitation of the hydroxide, see Eqs. 7 and 8.

As a result there are two principal regimes of coagulation. The first has a mechanism of charge neutralisation. Edwards and Amirtharajah (1985) have confirmed this mechanism by removing humic acids with stoichiometric doses of coagulant. This mechanism requires a $\mathrm{pH}$ of less than 6.5 and low ionic strength waters; coagulant overdosing may result in colloid restabilisation and thus worsen performance. This mechanism is particularly effective for the removal of dissolved natural organic material rather than colloidal particles (Jacangelo et al., 1995).

The second mechanism, which is called sweep coagulation, occurs when amorphous ferric hydroxide co-precipitates with the colloidal particles; the particles are trapped by the precipitate and settling occurs. This kind of coagulation/flocculation occurs at neutral $\mathrm{pH}$ 's and is understandably less sensitive to variations in the water quality than charge neutralisation (Jiang and Graham, 1998). Thus an effective flocculation process must be operated at a $\mathrm{pH}$ and coagulant concentration so that the ferric hydroxide precipitate will form. This means that for a particular $\mathrm{pH}$ there is a lower concentration limit, below which coagulation will not occur because it is thermodynamically unfavourable. On the other hand, the hydroxide must not form so quickly that it precipitates without interacting with the colloid particles.

The aim of the flocculation results presented in this paper was to investigate the effect of coagulant concentration on the flocculation achieved so as to minimise the amount of coagulant added.

\section{Experimental}

The ferric chloride $\left(\mathrm{FeCl}_{3} \cdot 6 \mathrm{H}_{2} \mathrm{O}\right)$ used in this study is supplied by Saarchem (99\%purity).

Jar tests are carried out using a Stuart Scientific flocculator (SW 1model) in order to determine the optimum coagulant dosage for the wastewater, which contains six stirrers with paddles according to the general procedure. (Faust and Aly, 1983; Hammer, 1977; Kemmer, 1988). Six beakers are used in an experiment, each containing $400 \mathrm{~m} \ell$ of wastewater. 20, 40, 60, 80, 100 or $120 \mathrm{~m} \ell$ of flocculent solution is added to the beaker. On addition of coagulant solution the wastewater is agitated at a speed of $250 \mathrm{rpm}$ for one minute to aid quick dispersion of the flocculent into all parts of the wastewater in the beaker. Formation of flocs is observed after about one and half minutes. The speed is reduced after ten minutes and six minutes later it is finally stopped so that sedimentation of flocs can occur. The contents of the beaker are allowed to settle for a further thirty minutes, so that the water above the sludge can be recovered.

Determination of the solid content of wastewater was done by drying a known mass of $20 \mathrm{~g}$ of wastewater in oven at $130^{\circ} \mathrm{C}$ for one hour. The solid content of wastewater of different samples varies and it was standardised to $80 \mathrm{~g}$ of solid per $1000 \mathrm{~g}$ of wastewater, in order to obtain comparable results. A solid content of $80 \mathrm{~g}$ of solid per $1000 \mathrm{~g}$ of wastewater was selected because it was the most dilute sample encountered. The wastewater generated in the paint production process is collected and stored in a vessel; it is agitated continuously for about two hours to ensure even dispersal of solid in colloids before sampling for the purposes of this study. The wastewater sample is kept in a sealed 5L container, and stirred at $300 \mathrm{rpm}$ for about one hour before the solid content of wastewater is measured.

Metal ion concentrations of water recovered were determined using a Varian Flame Atomic Adsorption spectrometer (Model: 
Spectra AA 55B). In the measurement of ferric ions, acetylene is used as fuel with air as support and the flame stoichiometry is oxidizing. For aluminium ions, acetylene is used as fuel the support is nitrous oxide. The flame stoichiometry is reducing.

Turbidity was measured with an infra-red Hanna Portable Microprocessor Turbidity Meter; the unit of measurement is Formazin Turbidity Unit (FTU). The $\mathrm{pH}$ meter is a CRISON micro pH 2002 model. Calibration is carried out using technical buffer solutions of 4 and 7.

\section{Results and discussion}

\section{Recycling wastewater}

The waste from the Barloworld Plascon SA plants is mainly a result of using water to wash the tanks, pipes, and filling machines used to produce and package the products. The products are produced in batches, with different products scheduled in the same vessels. This waste stream is therefore made up of dilute paint which until recently was all treated in a flocculation process with ferric chloride as the coagulant.

An opportunity was identified where the non-textured white wash water could be captured and reused in low quality white paints. As the wash water will be reused in low quality products, washings from low quality products are also captured.

During preliminary attempts to reuse the wash water concerns were raised due to biological and product contamination. Paint contains many organic ingredients, most notably cellulose thickeners and polymers, and is therefore prone to microbiological attack. There is an inherent risk that if the water is contaminated, and then used, the product made from the water would rapidly deteriorate with disastrous consequences on product quality and for the receiving market. In order to minimise risk, the process of collecting the wash water and treating it is almost fully automated and biocide is added to the water. In addition, an outside company tests the wash water collected for contamination every three weeks and a visual check of the water is done before use. The combination of all of these measures ensures that the wash water recovery system functions correctly and that there is no risk to the consumer.

The wash water storage vessel is agitated in order to prevent the heavier solids from settling and blocking the transfer lines. On average a batch of water is collected over about 3 days.

The volumes of feed water that the paint making process requires are dramatically larger than the amount of wash water produced. This provides an opportunity to completely empty the wash water storage vessel every time a batch of paint is made from the wash water. This has two distinct advantages in that the agitator is not required to operate continually, and more importantly, one batch of wash water is not mixed with the next batch. This reduces energy consumption, and further minimises the risk of contamination. The characteristics of the wash water are given in Figs 2 and 3.

The wash water feed contains an average of $12 \%$ solids, ranging from $7.6 \%$ to $18.6 \%$, see Figure 2 . The percentage solids in paint varies from 50 to $60 \%$. These solids are components of the products made so that recycling the wash water back into the process results in an improved product quality. In addition some savings of virgin raw materials are made. In particular, less rheology modifiers are required. The exact reduction varies from batch to batch as the mix of raw materials in the wash water varies.

The composition of the wash water depends on the production schedule, in other words, what is being washed away. Moreover, the exact volume of wash water is variable since the washing is done manually. At present precise information on the quantity and

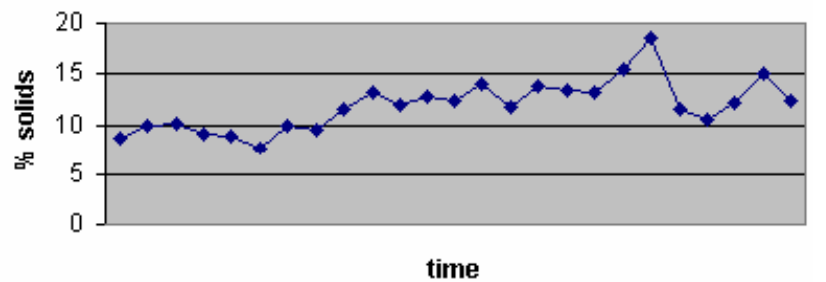

Figure 2

Percentage solids in wash water reused

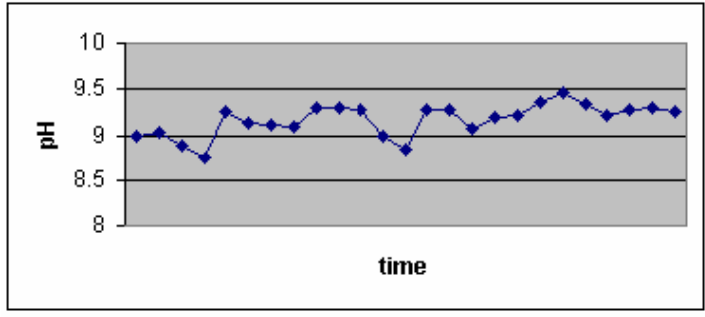

Figure 3

$\mathrm{pH}$ of wash water reused

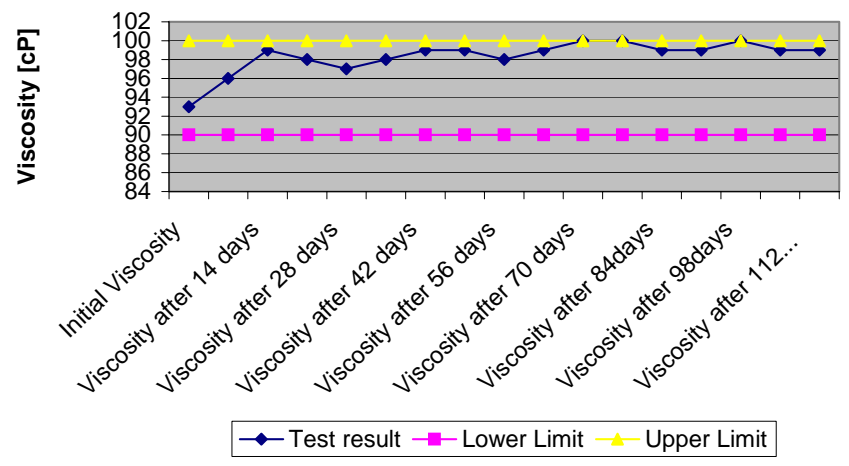

Figure 4

Viscosity stability after $115 d$

nature of the wash water is not available. If this information were known, further reductions in raw materials would be possible.

The $\mathrm{pH}$ of the wash water varies from 8.7 to 9.5 and is shown in Fig. 3. This is somewhat higher than the $\mathrm{pH}$ of feed water. Since some of the components of the product are also basic, the high $\mathrm{pH}$ of the wash water does not affect the final product quality.

\section{Results of the wastewater reuse to date}

The products made from the wash water are carefully monitored over an extended period to determine if there are any long term consequences for the product as a result of the use of the wash water. To date, the results have been excellent. All of the critical parameters that are monitored are well within the required specifications and have remained stable. In Figure 4 results for viscosity, one of the critical parameters of the receiving products, are plotted.

The viscosity increases fairly quickly at first and then levels off at a value just below the upper limit. After 115 days the viscosity was still within this limit.

\section{Treatment of waste in order to minimise coagulant usage and sludge production}

In Table 1 the results are shown of the experiment that was used to determine the volume of ferric chloride solution required to effect good flocculation of wastewater without overdosing. The same 
TABLE 1

Flocculation of wastewater

\begin{tabular}{|c|c|c|c|c|c|c|}
\hline Jar number & 1 & 2 & 3 & 4 & 5 & 6 \\
\hline Volume of wastewater ( $80 \mathrm{~g}$ solids $/ \mathrm{kg})(\mathrm{m} \ell)$ & 400 & 400 & 400 & 400 & 400 & 400 \\
\hline Volume of $7 \mathrm{~g} / \ell \mathrm{FeCl}_{3}$ added $(\mathrm{m} \ell)$ & 20 & 40 & 60 & 80 & 100 & 120 \\
\hline $\mathrm{FeCl}_{3}$ concentration $(\mathrm{g} / \ell)$ & 0.33 & 0.64 & 0.91 & $1.17^{*}$ & $1.40^{*}$ & $1.62^{*}$ \\
\hline
\end{tabular}

\begin{tabular}{|c|c|c|c|c|c|c|}
\hline \multicolumn{7}{|c|}{$\begin{array}{c}\text { TABLE } 2 \\
\text { Flocculation for different feed concentrations of } \mathrm{FeCl}_{3}\end{array}$} \\
\hline Feed & \multicolumn{6}{|c|}{ Ferric chloride $\left(\mathrm{FeCl}_{3}\right)$ concentration in test jar $(\mathrm{g} / \ell)$} \\
\hline 7 & 0.33 & 0.64 & 0.91 & $1.17^{*}$ & $1.40^{*}$ & $1.62 *$ \\
\hline 52 & 0.35 & 0.66 & 0.95 & $1.21 \#$ & $1.46 \#$ & $1.69 \#$ \\
\hline 109 & 0.32 & 0.62 & 0.89 & 1.13 & $1.37 \#$ & $1.58 \#$ \\
\hline 607 & 0.76 & 0.91 & 1.06 & $1.21 \#$ & 1.36\# & $1.51 \#$ \\
\hline
\end{tabular}

(*) Points where good flocculation occurs, i.e. there is recovery of clear water and a well formed sludge.

(\#) Immediate formation of large flocs and incomplete removal of solids.

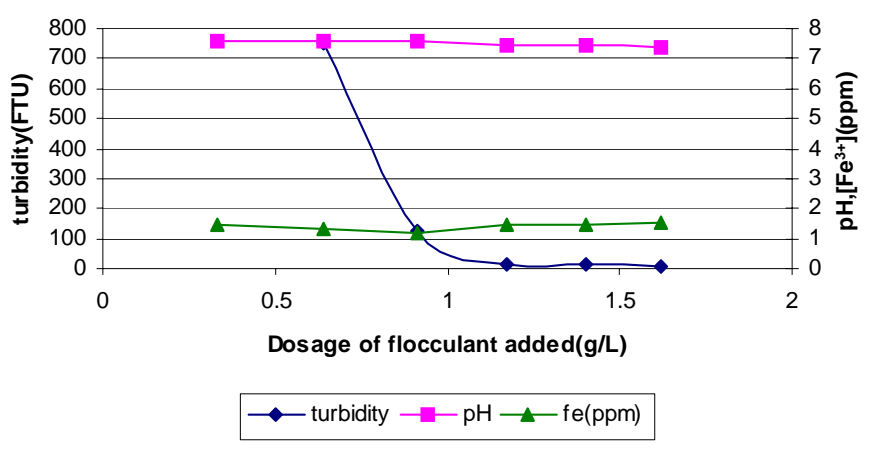

Figure 5

Results of experiment using $7 g / l$ ferric chloride coagulant solution

volume of wastewater was added to each beaker, namely $400 \mathrm{~m} \ell$, but the volume of $\mathrm{FeCl}_{3}$ was varied. Table 1 shows the concentration that corresponds to the volume of ferric chloride dosed into each jar. The concentrations at which flocculation occurs are marked with asterisks $(*)$. It can be seen that the onset of flocculation occurs for ferric chloride between a concentration of 0.91 and $1.17 \mathrm{~g} / \ell$.

In order to investigate the effect of ferric chloride feed concentration the following solutions were prepared: 52, 109 and $607 \mathrm{~g} / \ell$. In a similar way to the experiment for which the results are shown in Table 1, various volumes of these solutions were added to wastewater to test for flocculation. The results are given in Table 2.

The onset of flocculation occurs at the dosages indicated by either asterisks (*) or hashes (\#), namely: 1.17, 1.21, 1.37 and 1.21 $\mathrm{g} / \ell$ for the 7, 52, 109 and $607 \mathrm{~g} / \ell$ feed solutions. It is interesting to note that the 1.17 and $1.21 \mathrm{~g} / \ell$ tests resulted in coagulation and flocculation, however the $1.13 \mathrm{~g} / \ell$ test did not. This implies that the lower ferric chloride concentration limit for coagulation is between $1.13 \mathrm{~g} / \ell$ and $1.17 \mathrm{~g} / \ell$. In other words insufficient coagulant was added to the $1.13 \mathrm{~g} / \ell$ beaker for coagulation to occur.

For all of the higher concentration feed solutions the coagulation occurred immediately on addition of the coagulant and the flocs formed were large, this is indicated by \#. This is in contrast to the addition of a $7 \mathrm{~g} / \ell$ feed solution that favours gradual growth of fine floc particles. Moreover the liquid recovered on addition of highly concentrated ferric chloride feed was still milky after flocculation, for all cases. The sludge formed using highly concentrated ferric chloride is coarse in nature and lumpy. The coarse flocs tend to float on the surface of the water rather than settle out.

These results can be explained as follows. It was mentioned in the introduction that there is competition between the precipitation of ferric hydroxides and the interaction of hydrolysed ferric species with the colloidal particles of the suspension. In the case of low ferric feed concentrations ( $7 \mathrm{~g} / \ell$ ), the precipitation reaction is slow, so that the ferric polycations react with colloid particles. For all of the higher concentration ferric chloride feed solutions the precipitation reaction is accelerated by the higher ferric concentration. As soon as the coagulant comes into to contact with hydroxide ions in the wastewater, it precipitates. The flocs formed have a much higher ferric content, so that the same amount of coagulant only partially removes the colloidal particles and the water remains milky. In other words the coagulant is used inefficiently.

The results of the $7 \mathrm{~g} / \ell$ experiment are given in more detail in Fig. 5. The following data has been plotted: turbidity (which is shown on the left hand vertical axis), $\mathrm{pH}$ and the concentration of iron in the clear solution recovered after flocculation (shown on the right hand axis) as a function of the volume of ferric chloride feed solution added. The turbidity of the solution in which concentration of ferric chloride was $0.33 \mathrm{~g} / \ell$ on addition of ferric chloride of $20 \mathrm{~m} \ell$ was too high to obtain a reading. The turbidity decreases sharply at first and then once the concentration of ferric chloride in wastewater reached $1.4 \mathrm{~g} / \ell$, on addition of about $80 \mathrm{~m} \ell$ of coagulant added it levels of at about 11 FTU. The $\mathrm{pH}$ of the water recovered decreases marginally as more ferric chloride is added and lies in the range of 7.3 to 7.5.The concentration of iron in clear liquid recovered after flocculation remains approximately constant and is less than $1.5 \mathrm{ppm}$. This is low in comparison to concentration of ferric ions in the test beaker which ranged from 330 ppm to 1620 ppm. This clearly indicates that the bulk of the ferric ions are resident in the sludge.

The metallic content of the recovered water is within effluent disposal standards. The effluent disposal limit for ferric ions is 
5ppm and reuse standard is $0.04 \mathrm{ppm}$.(Gisclon et al., 2002). The $\mathrm{pH}$ of the water recovered was around neutral and within the effluent disposal limits.

The amount of ferric chloride that needs to be dosed must be adjusted according to the solid content of the wastewater. Provided the ferric chloride is dosed correctly, the waste generated is not hazardous.

Using a low concentration ferric chloride solution has the disadvantage that larger volumes of wastewater are generated, and additional feed water is required to dilute the ferric chloride solution. There is a trade-off between the additional water required and the reduction in ferric chloride used.

\section{Conclusions}

\section{What is the benefit to the environment and to Barloworld Plascon SA}

On the basis of current operation approximately 190kL of wash water would be reused annually. (There is some unrealised potential for increasing this.) This represents an estimated $20 \%$ of the total waste stream from the plant. There are savings in terms of reduced quantity of sludge to be disposed of, reduced ferric chloride required for sludge treatment and reduced quantities of rheology modifier.

The calculation is indicated more clearly below:

\begin{tabular}{|c|c|}
\hline Mass of wash water reused since & $186051 \mathrm{~kg}$ \\
\hline \multicolumn{2}{|l|}{ September 2003} \\
\hline Average solids in the wash water & $12 \%$ \\
\hline Solids content in the sludge & $98 \%$ \\
\hline $\begin{array}{l}\text { Mass of sludge is therefore } \\
\text { (186 } 051 \mathrm{~kg} \times 0.12 \text { / 0.98) }\end{array}$ & 22782 kg \\
\hline Disposal cost is & R340/ ton \\
\hline Savings on disposal cost & R7 700 \\
\hline Ferric chloride saving (@4c/l treatment cost) & R7 500 \\
\hline $\begin{array}{l}\text { Rheology modifier saving (Acrysol TT935 } \\
\text { @ R12.86 /kg) on } 48 \text { batches of paint } \\
\text { ( } 48 \text { x 95kg/batch x R12.86) }\end{array}$ & R58 600 \\
\hline $\begin{array}{l}\text { Total savings from wash water reuse } \\
\text { (on an annual basis) }\end{array}$ & R73 800 \\
\hline
\end{tabular}

Due to the ineffective use of ferric chloride the waste is classified as hazardous. The avoidance of this waste is therefore of great environmental importance, even though the financial benefits are small.

Based on the results obtained from the flocculation experiments the following conclusions may be drawn. The wastewater generated contains solid content that varies with every batch, therefore a constant dosage of coagulant cannot be used to treat paint wastewater. Analysis of solid content of different samples of wastewater should be carried out before coagulation and flocculation. Dosage of coagulants for wastewater treatment can be based on the quantity of solids in wastewater, in order to avoid overdosing. The flocculation of wastewater at high concentration of flocculants leads to inefficient use of the coagulant due to the high rate of hydroxide precipitation.

Using low concentration ferric chloride solutions has the disadvantage that larger volumes of wastewater are generated, and additional feed water is required to dilute the ferric chloride solution. There is a trade-off between the additional water required and the reduction in ferric chloride used.

The $\mathrm{pH}$ and metal ion content of the water recovered are within the effluent limits, however the turbidity is not.

The sludge produced in the experiment contains the bulk of the flocculent. Therefore a careful study of the sludge is essential before the sludge can be recycled.

Barloworld is a company dedicated to good environmental practice.

\section{References}

BOTTERO JY, CASES JM, FIESSENGER F and POIRIER JE (1980) Studies of hydrolyzed aluminium chloride solutions. 1. Nature of aluminium species and composition of aqueous solutions. J. Phys. Chem. 84 2933-2939.

CANO-RUIZ JA and McRAE GJ (1998) Environmentally conscious chemical process design. Annu. Rev. Energy Environ. 23 499-536.

EDWARDS GA and AMIRTHARAJAH A (1985) Removing color caused by humic acids. J. AWWA 77 (3) 50-57.

FLYNN CM (1984) Hydrolysis of inorganic iron (III) salts. Chem. Rev. 84 31-41.

GISCLON A, McCARLEY S and McNALLY K (2002) The Durban water recycling project - The vision becomes reality. Paper presented at Biennial Conference of the Water Institute of South Africa, 19-23 May 2002, Durban, South Africa.

HAMMER JM (1977) Water and Waste-Water Technology. John Wiley, New York. 37 pp.

JACANGELO JG, DeMARCO J, OWEN DM and RANDTKE SJ (1995) Selected processes for removing NOM: An overview J. AWWA 87 (1) 64-77.

JIANG J-Q and GRAHAM NJD (1997) Pre-polymerised inorganic coagulants for treating water and waste water. Chemistry and Industry $\mathbf{1 0}$ 388-391.

JIANG J-Q and GRAHAM NJD (1998) Pre-polymerised inorganic coagulants and phosphorus removal by coagulation - A review. Water SA 24 (3) $237-244$

KEMMER FM (1988) (ed.) The Nalco Water Handbook (2 ${ }^{\text {nd }}$ edn.), McGraw-Hill, New York. 8.3-8.23.

MAGINI M (1977) Structural relationships between colloidal solutions and hydroxide gels of iron (III) nitrate. J. Inorg. Nucl. Chem. 39 409412.

PEAVY HS, ROWE DR and TCHOBANOGLOUS G (1985) Environmental Engineering. McGraw-Hill, Singapore. 131-140. 